\title{
ENTREPRENEURIAL EXPORTING STRATEGIES: CONTRACTUAL CONSIDERATIONS
}

\author{
Andrew L. Zacharakis \\ Babson College \\ Babson Park, MA
}

\begin{abstract}
The best opportunity for growth is often overseas, even for smaller entrepreneurial firms. However, resource constrained smaller firms do not have as many available entry strategies as do larger Multinational Corporations (MNCs). Smaller firms frequently must ally themselves with partners in order to make international expansion feasible. The alliance of two distinct parties central to these entry strategies lends itself to an Agency Theory (AT) perspective. AT illuminates the underpinnings of these relationships; in particular, highlighting problems and risks that the respective parties face when entering into the partnership. The paper develops these problems within the entrepreneur/export agent realm and suggests contractual methods for overcoming these problems.
\end{abstract}

\section{Introduction}

Betsy Seabert, International Manager of Spyder Active Sports Inc., recently observed...

"[Our Norway Distributor] is only selling the racing pants, sweaters, and a couple of jackets. We have this great line for which the agent does not even purchase samples. We know that there has to be people in Norway that would be interested in [our entire line]."

"[We] receive reports on what they have ordered, but I do not have copies of orders or to whom they have sold. I could go over there and research each shop if I wanted to, but I do not have the time...also a company our size has to really watch [expenses]."

"There have been problems in the past with collecting money long distance. We were not reimbursed for products shipped....It is not usually worth the expense [to enforce our contracts]."

The above observations exemplify the difficulty of international operations, especially for small entrepreneurial firms. The small firm often worries about whether its foreign agents are acting in the firm's best interest. Small firms are 
likely to suffer some broken contracts and they do not have the resources to either do more of the work themselves or keep tabs on their foreign operations. Nevertheless, the potential opportunities of international expansion may outweigh the risks, even for small businesses. In fact, international expansion by small entrepreneurial organizations, or what Oviatt \& McDougall (1994) call International New Ventures (INVs), is increasing (Brokaw, 1990) which suggests that these firms perceive international opportunities. The number of smaller firms exporting goods has increased by over 22 percent since $1987-150$ percent increase in the dollar value of those goods (Brown, 1995) - to the point where 96 percent of all U.S. exporters are firms with less than 500 employees (Prosak, 1993). Although entrepreneurs are exploring opportunities overseas more frequently, the research related to this topic has been somewhat ignored (Oviatt \& McDougall, 1994).

This paper explores the potential difficulties that smaller entrepreneurial organizations face when entering the international environment; particularly focusing on the partnerships that entrepreneurs often use for entry. Since entrepreneurial firms are typically resource constrained, they must leverage their resources in order to successfully enter an international market. Utilizing a partner with some knowledge of the target market, or what Oviatt \& McDougall (1994) call hybrid entry strategies (i.e. export agent, licensing, joint ventures, strategic alliances - see appendix for definitions of these terms), can help leverage the entrepreneur's resources. The real issue for the entrepreneur is picking the right party with which to ally. Does the party possess the necessary skills to facilitate successful expansion? Will the party perform as promised? How can the entrepreneur ensure that performance? In sum, the entrepreneur may be susceptible to informed partners who may or may not share the entrepreneur's goals.

Recognizing and managing the information discrepancy (i.e. the entrepreneur does not know enough about the potential partner to ensure that they have the same goals and work ethic), or information asymmetry, is a cornerstone of Agency Theory (Rumelt, Schendel, \& Teece, 1991). The primary objective of the Principal-Agent branch of Agency Theory is to highlight the discrepancies in knowledge between the two parties and derive a proper governance structure to minimize problems (Eisenhardt, 1989). Agency Theory highlights the diverse goals between entrepreneurs and their partners; it also suggests how such diversity can be managed. Moreover, depending upon which country the entrepreneur is interested in expanding, Agency Theory can illustrate how the relationship might be structured.

\section{Agency Theory}

Agency Theory is closely related to Transaction Cost Economics (Mahoney, 1992a; Williamson, 1988). Transaction Cost Economics has been widely used in studying international business (e.g. Contractor, 1990; Hennart, 1988, 1990; 
Rugman \& Verbeke, 1992; Shane, 1992, 1993). Both theories address governance in the face of opportunism (i.e. one party seeks self interested gains "with guile" at the expense of the other [Williamson, 1988]). Each theory posits that opportunism can be controlled via contracting. Whereas Agency Theory focuses on ex ante alignment of incentives, Transaction Cost Economics is concerned with ex post governance issues such as dispute resolution (Mahoney, 1992b). Although there are many subtle differences between the two theories, the difference of central importance to the current paper is that of information asymmetry (Rumelt, Schendel \& Teece, 1991). Agency Theory focuses on the individuals involved in the partnership (versus the transaction) and how different knowledge (asymmetric information) may allow one party to take advantage of the other party. Asymmetric information is especially problematic when the two parties have conflicting goals or desires (Eisenhardt, 1989).

\section{Agency Theory as a Framework for International Entrepreneurial Expansion}

Agency Theory provides insight and guidance for entrepreneurs considering international expansion. Given the relatively small size of most entrepreneurial firms (versus larger MNCs) and the subsequent scarcity of excess resources possessed by these firms, the entrepreneurial firm may need to leverage its available resources in order to make international expansion plausible. Thus, entrepreneurial firms (or INVs) typically resort to one of the hybrid entry strategies (McDougall, Shane \& Oviatt, 1994) mentioned earlier.' The unifying denominator between each of these entry strategies is that entrepreneur's (principal) ally themselves with a partner (export agent) in order to leverage their resources and make international expansion more affordable, as well as increasing the likelihood of successful entry.

\section{Information Asymmetry}

In order for both parties to benefit from the relationship, each must contribute some specialized knowledge that the other is lacking; or as Lawless \& Price (1992) assert, each party must possess asymmetric information. For example, Spyder - the ski clothing manufacturer introduced at the beginning of the paper - possesses the knowledge and skill of designing and producing highly desirable ski accessories. The export agent contributes an in-depth knowledge of the target market. Each party possesses valuable information that the other party can utilize; the export agent wants a good product to sell and the entrepreneur wants

\footnotetext{
'Agency Theory can apply to any relationship where the principal delegates responsibility to an agent. Within the international context described in this paper, Agency Theory could apply to any of the hybrid entry strategies (licensing, joint ventures, strategic alliances, etc.) described by Oviatt and McDougall (1994). In an effort to simplify and focus the discussion, the current paper focuses on an entrepreneur/export agent scenario.
} 
a knowledgeable and skilled salesperson. Thus, as Lawless \& Price (1992) point out, asymmetric information can have positive implications. If each party possesses the requisite skill and each party's asymmetric knowledge complements that of the other party, entry success is apt to be greater.

Proposition 1a: All else equal, each party's special knowledge (information asymmetry) increases the overall chances of entry success.

However, asymmetric knowledge (as the majority of Agency Theory literature highlights) also provides the basis for opportunistic activity that may be detrimental to the other party. Opportunistic behavior may so damage the partnership, that it is dissolved. Even if the relationship remains intact, the lost "trust" may impede the two parties from effectively working together to the point where entry success is diminished. Thus, each party prefers that the relationship be structured in a manner such that opportunistic behavior is dissuaded.

Proposition 1b: All else equal, opportunistic behavior on the
part of either party will decrease the chances for successful
entry.

\section{Conflict of Interest}

Eisenhardt (1989) highlights two major problems associated with the agency relationship. First, the principal and agent generally have conflicting goals. Moreover, it is often difficult and expensive for principals to verify that agents are complying with the entrepreneur's goal. For example, Spyder wants its full line sold in Norway while the export agent prefers only to sell the popular (and higher margin) ski pants. The verification problem is exemplified by two behaviors discussed in Agency Theory - adverse selection and moral hazard. Adverse selection occurs when one party misrepresents their abilities to the other (Bergen, Dutta \& Walker, 1987; Eisenhardt, 1989). Moral hazard occurs when one party does not put forth the level of effort agreed upon (Bergen, Dutta \& Walker, 1987; Eisenhardt, 1989). The potential threat of these behaviors leads each party to a differing structure preference for the partnership.

A second major problem generated by principal/agent structures is that the principal and agent are quite likely to have different attitudes towards risk. Traditional Agency Theory suggests that agents are more risk averse than principals because they cannot diversify their employment (Eisenhardt, 1989). Principals, by extension, are risk neutral (Eisenhardt, 1989). Within the international scenario, the traditional interpretation of risk differences may not be applicable. For instance, entrepreneurs (principal) may offer their agents an "exclusive" for any particular target market which precludes entrepreneurs from diversifying their risk (i.e. using other agents in the target country). The agents, on the other hand, 
may be able to represent several organizations (thereby becoming risk neutral). Regardless of each participant's risk attitude, the agency relationship is one of dependency where each party can be adversely affected by the actions of the other. Therefore, each party wants to structure the relationship in such a way as to limit their risk exposure.

Divergent goals and different risk preferences increase the cost of the relationship between the principals and agents because each respective party wants to structure the relationship in a manner that best meets their needs while reducing risks to an acceptable level. Agency Theory suggests that these problems are handled via a "nexus of contracts" (which Jensen \& Meckling define "as a multitude of complex relationships... between [the firm] and... labor..." 1976, p. 311). ${ }^{2}$ Further, the theory suggests a continuum of contract types, ranging from behavior-oriented to outcome-oriented (Eisenhardt, 1989).

Outcome-oriented contracts focus on the principal's (entrepreneur's) desired outcome. For example, the entrepreneur (principal) may contract for the sale of 200 ski jackets in Europe. The outcome-oriented contract is based on the end result and not the method of selling the jackets. Since the end result is the same for both parties (sell 200 jackets), outcome-oriented contracts align the principal's and the agent's interest. Aligning interests reduces the threat that agents will misrepresent themselves (adverse selection) or shirk (moral hazard) because doing so exposes agents to losses (i.e. they eat the cost of the 200 ski jackets). Outcome contracts are favored by entrepreneurs because these contracts shift the risk and uncertainty of meeting a certain outcome to the export agent.

Behavior-oriented contracts focus on the "means" of achieving the entrepreneur's goal. Thus, a behavior-oriented contract might emphasize the number of outlets, price level, or some other factors affecting the method of selling jackets. To ensure that the agent puts forth the effort agreed upon, the entrepreneur must monitor the agent's behavior. If the agent does not sell the targeted level of jackets, the agent is not liable as long as (s)he conformed to the behaviors outlined in the agreement (e.g. met with 50 retail outlets during the year). Agents prefer behavior based contracts because they are not exposed to risk from outside factors that might impede their efforts (e.g., downturn in the economy, below average snow fall, etc.). Unfortunately, from a managerial perspective, the principal generally incurs the cost of verifying the agent's actions in this type of contract. However, monitoring costs may be offset to the extent that agents wish to protect their reputation (Donaldson, 1990; Larson, 1992). The reputation effect assumes either that the principal and agent will conduct business in the future or

\footnotetext{
${ }^{2}$ The term "contract" should be thought of as a metaphor; contracts describe relationships in which one party delegates responsibility to another (Rugman \& Verbeke, 1992). The contract is not necessarily a formal, written contract, but may be a set of expectations between the parties that are not necessarily verbalized, let alone documented (Brown, 1995).
} 
that the principal can diminish the agent's reputation to other potential principals. In order to reduce monitoring costs, principals also may attempt to bond the agent via guarantees, third party auditing, contractual limits on the agent's authority, and compensation agreements if the agent does take certain liberties (Jensen \& Meckling, 1976). The next section further explores the issues and why they are particularly relevant for an entrepreneur considering international expansion.

\section{The Agency Costs to Entrepreneurs of International Expansion}

The agency issues raised by this relationship stem directly from the risks inherent in the expansion decision, and from the likelihood of divergent goals between the entrepreneur and the international agent. Differing goals and desires as outlined above frequently cause problems between entrepreneurs and agents; in particular, the aforementioned adverse selection and moral hazard.

\section{Adverse Selection}

Adverse selection is problematic because agents have asymmetric information regarding their own abilities. Conlon \& Parks (1988) find that the principal's typically strong information network (or capability to verify an agent's ability) favors a behavioral based contract. However, Conlon \& Parks' (1988) research focuses on large organizations (retailers) and their ability to gain information about their salespeople (agents). Unlike principals in the majority of Agency Theory research, relatively resource constrained entrepreneurs may find it difficult to obtain good information about their agents. Therefore, entrepreneurs may be more likely to favor outcome based contracts.

Several factors make adverse selection especially troublesome for entrepreneurs. First, entrepreneurs are relatively resource constrained (Stinchcombe, 1965, Vesper, 1990) compared with larger MNCs that operate internationally. Thus, the entrepreneur may be less able to verify the agent's credibility. The small organization often relies on the agent's resume, referrals, and the "grapevine" (i.e., talk at international trade shows) to judge the agent's ability and trustworthiness. However, these sources of information may not be nearly as reliable as those possessed by larger MNCs. MNCs, for example, are more likely familiar with the agent's reputation, because the MNC is tuned into the industry's "gossip circle that tells who is honorable, tough, sleazy and so on" (Pratt \& Zeckhauser, 1985, p. 13). The entrepreneur in the current paper's scenario, on the other hand, is likely new to the international arena and, by extension, less connected to the industry's "gossip circle."

Second, the distance between the home market and the target market also impedes verification because it increases the cost of communication and travel. Differences in language and culture further affect understanding about goals, risks and the development of adequate contracts. The principal and agent may not be able to achieve or maintain a "meeting of the minds." Again, the principal 
bears the risk of incurring extra costs to overcome any potential misunderstandings. These extra costs can be especially burdensome to smaller entrepreneurial organizations.

Finally, entrepreneurs, as relatively small players, can rely much less on the reputation effect (Donaldson, 1990; Larson, 1992) than larger firms, because their power over agents is limited. Therefore, "trust" relationships (Lawless \& Price, 1992), while the ideal, may subject the entrepreneurial firm to a heightened level of risk. For example, the agent may enter into a contract for a quick profit, realizing that the entrepreneur will not be able to adequately monitor or enforce the contract. Thus, entrepreneurs are likely to favor an outcome based contract because of the protection it provides.

\section{Moral Hazard}

Agency theory posits that agents shirk, or do not live up to their contracts where possible. Moral hazard relates to information asymmetry in that the entrepreneur cannot easily obtain information about the export agent's performance. Eisenhardt (1985) and others (e.g., Brickley \& Dark, 1987) find that the more difficult it is to monitor the agent's behavior, the more likely the principal will use an outcome contract. Several of the issues raised with respect to adverse selection apply to moral hazard as well. Since entrepreneurs are resource constrained, the costs involved of adequately monitoring the agent's behavior may be overwhelming, especially considering the distance between the two parties. In addition, different cultural norms may lead entrepreneurs to believe that agents are shirking, but in reality, the agents are performing within the expected norms of their culture. For example, completing deals in Japan can be time consuming since Japanese business people value relationships. Thus, the amount of time that Japanese export agents spend making small talk might surprise American entrepreneurs. To impatient Americans, the small talk and dinner appointments that can literally take days during the initial contact between two new business partners can seem like a huge waste of time and money. An American entrepreneur unfamiliar with Japanese cultural norms might assume her/his Japanese agent is shirking. Yet, the development of a personal relationship is crucial to long term success in Japan. Therefore, American entrepreneurs would likely prefer to contract on an outcome basis versus a behavior basis because such contracts focus on the end result rather than how business is conducted. Moreover, outcome-oriented contracts reduce the need for monitoring and align the interests of principals and agents (Jensen \& Meckling, 1976). Thus, entrepreneurs are apt to prefer outcome-oriented contracts.

\section{Risk Aversion}

Each party anticipates benefits from a joint relationship, but recognizes that there is risk in the endeavor. Thus, each would like the other to shoulder as much of the risk as possible (i.e., the entrepreneur wants the export agent to shoulder 
most of the risk and vice versa). Eisenhardt (1985) finds that agents prefer behavioral based contracts because such contracts reduce their risk. Likewise, entrepreneurs likely favor outcome based contracts. As mentioned earlier, principals (entrepreneurs) are more risk averse because it may be difficult to diversify their use of agents in any one market. Additionally, Brickley \& Dark (1987) find that franchising (using an agent) is preferable when environmental uncertainty is high (just as it might be in the international area). A franchise can be viewed as an outcome contract, because the franchisee's interests are aligned with the franchiser's ("sell as many units as possible"). It is likely that international expansion causes entrepreneurs additional concern due to their unfamiliarity of the target market and their added reliance on others for success.

Entrepreneurs entering foreign markets may tend to be risk averse for several reasons. First, entrepreneurs are entering an unfamiliar market. It is far more difficult for the entrepreneur to derive accurate estimates of future outcomes in the new international market than in the entrepreneur's existing areas of operation. Thus, the "uncertainty" of future events (Ring \& Van de Ven, 1994) is compounded by unfamiliarity of the target market. The foreign market's preferences are likely to vary dramatically from the entrepreneur's home market due to culture, language, political, and environmental differences. This unfamiliar market raises the entrepreneur's uncertainty. The agent, on the other hand, is highly familiar with the target market. Therefore, the export agent does not perceive the same level of risk in relation to the market as does the entrepreneur.

Another reason that the entrepreneur may be risk averse is that entrepreneurs are typically relatively smaller in comparison to other international players; which implies relatively limited resources. Thus, they tend to be cautious when exploring different uses for their resources. Limited resources in conjunction with geographical distance makes the control and monitoring of any international relationship more tenuous.

Since the entrepreneurial firm may be risk averse and susceptible to adverse selection and moral hazard, the entrepreneur prefers an outcome-oriented contract. The outcome-oriented contract shifts risk to the agent (Eisenhardt, 1989). The preceding discussion leads to the following proposition:

\begin{abstract}
Proposition 2: All else being equal, the added uncertainty of operating in foreign markets, in combination with the threat of adverse selection and moral hazard involving an export agent, encourages entrepreneurial firms to negotiate for outcomebased contracts (versus behavior-based contracts) in order to shift risk to the agent.
\end{abstract}

\title{
Export Agent Preference
}

The export agent faces many of the same issues as the entrepreneur adverse selection, moral hazard and risk aversion. In order to secure the agent's 
services, the entrepreneur may misrepresent the product's true potential (a case of adverse selection). Just as the entrepreneur lacks complete knowledge about the agent, the agent lacks complete knowledge about the entrepreneur, especially since it is often difficult to get good secondary information about relatively new entrepreneurial organizations (versus larger more established MNCs). Thus, agents are assuming substantially more risk in aligning themselves with relatively smaller entrepreneurial organizations than if they aligned themselves with larger MNCs. Once the relationship has been established, the entrepreneur may fail to execute. For example, the entrepreneurial firm may not meet the agent's orders in a timely fashion which could adversely affect the agent's reputation (a case of moral hazard).

The foreign agents that entrepreneurs are likely to deal with may also tend to be risk averse. Just like the entrepreneur, the agent may also face the problems of geographical distance, and a different language and culture from the entrepreneur. In addition, the agent is likely to be relatively small. The smaller the principal organization is, the smaller the volume of business conducted between the principal and agent, which suggests small scale agents will dominate. Since the agent is likely to be relatively small, the agent also tends to be resource constrained and relatively cautious. These circumstances raise the agent's uncertainty.

The risk averse agent likely prefers a behavior-oriented contract, because the agent is not obligated to reach a certain outcome. Instead, the agent is only required to perform in a certain manner (e.g., meet with thirty perspective clients in a month, etc.) versus achieving some end specified in an outcome contract (e.g. sell 3000 ski gloves a month). Thus, risk is shifted to the entrepreneur. The above discussion leads to the following proposition:

Proposition 3: All else being equal, the added uncertainty of dealing with a foreign entrepreneur, in combination with the threat of adverse selection and moral hazard encourages the agent to negotiate for a behavior-based contract (versus an outcome-based contract) in order to shift risk to the entrepreneur.

The difference in contract desires means that it costs entrepreneurs more to shift the risk to the agent, especially since entrepreneurs lack power to enforce their will. Therefore, the entrepreneur has to weigh the added monitoring costs associated with a behavior-oriented contract against the added cost to shift the risk to the agent associated with an outcome-oriented contract. A common method of solving this contract dichotomy is bonding.

\section{Bonding}

Bonding (the use of appropriate incentives to dissuade agents from acting opportunistically) makes behavior-oriented contracts more closely represent out- 
come-oriented contracts, because it shifts monitoring costs to the agent (Jensen \& Meckling, 1976). As the quotations from the example cited at the beginning of this paper illustrate, entrepreneurs may have difficulty enforcing international contracts. Bonding empowers the entrepreneurial firm by enabling it to more easily and efficiently enforce its contracts. There are several possible bonding avenues available for international transactions, including forum selection clauses, arbitration agreements, letters of credit, and escrow accounts.

Forum selection clauses enable the entrepreneur to specify where any disputes should be settled. Thus, if the entrepreneur is a U.S. firm, it might stipulate that all disputes be settled in the United States. Similarly, an arbitration agreement specifies that any dispute be heard by an arbitrator instead of a court. Arbitration ideally saves both parties considerable legal expenses. The entrepreneur can also demand a letter of credit through a bank in its home country; if the agent organization balks on fulfilling its obligations, the entrepreneur can enforce the letter of credit. Since the letter of credit is through a home-country bank, the entrepreneur can avoid any uncertainty or misunderstanding that might result from different legal standards in the international country. Again, such an arrangement reduces the entrepreneur's costs. Another alternative might be an agent escrow account. An escrow account accomplishes similar objectives as the letter of credit, but increases the agent's bonding costs. Thus, an escrow account will probably be used only if the agent is unable to obtain a letter of credit.

Since the entrepreneur lacks the power to dictate a purely outcome-oriented contract, bonding helps reconcile the entrepreneur's desire for an outcome-oriented contract and the agent's desire for a behavior oriented contract. Bonding effectively moves a behavior based contract towards an outcome based contract. Regardless of the method, bonding can reduce the entrepreneur's monitoring costs. The bonding discussion leads to the following proposition:

\section{Proposition 4: Since entrepreneurs and agents have different contract desires, most contracts will include bonding stipula- tions which reconcile a behavior-oriented contract with an out- come-oriented contract.}

\section{Cultural Differences Among Target Markets}

While the simplified Agency Theory framework provides direction to the entrepreneur considering international expansion, it may not provide the best basis for establishing a long-term, efficient, equitable and productive relationship. The basic Agency framework assumes that the relationship is one of opportunism as a function of information asymmetry. In other words, the parties to the relationship (especially the agent) take advantage of their position to the detriment of the other party. While this most certainly does happen, it is not cast in stone. Trust mitigates opportunism (Ouchi, 1980). Moreover, if both parties enter the relationship assuming the worst, it may have negative effects on the overall 
performance of the relationship (Bazerman \& Carroll, 1987; Neale \& Northcraft, 1991). The entry is more likely to succeed if the entrepreneur and export agent trust each other and, by extension, demonstrate that trust during the establishment of the relationship. Unfortunately, the entrepreneur cannot blindly demonstrate trust in all target markets by automatically using behavior based contracting; such a move would be dangerous. Thus, the basic Agency Theory framework should be modified to account for potential differences in the threat of opportunistic activity.

Possibly a good place to start might be to adjust the basic framework based upon the target country's culture or aptitude to be more opportunistic or altruistic. If an export agent is from a culture which dissuades opportunistic behavior, then the entrepreneur can negotiate a behavior based contract without greatly increasing the risk. In essence, people from trusting cultures automatically align their own interests with that of the entrepreneur because agent's from these cultures are less apt to misrepresent themselves (adverse selection) or shirk (moral hazard). Therefore, behavior based contracts may approximate outcome based contracts. In essence, entrepreneurs may adjust their contract desires based upon the target market's trustworthiness. The more trustworthy the target country, the more likely the entrepreneur will prefer a behavior contract and vice versa. The question is how do resource-constrained entrepreneurs identify which countries are more trustworthy?

Shane $(1992,1993)$ uses Hofstede's (1980) power distance index as a gauge of cultural trustworthiness. The power distance index represents the degree that members of a particular society expect power to be equally distributed in organizations (Hofstede, 1980). Stated differently, power distance is the degree to which inequality exists in a society (Hofstede, 1980). Hofstede notes that inequality exists on a number of different dimensions, such as prestige, wealth and power. For example, if a society has a large disparity between the wealthiest and poorest citizens, it has a high power distance. Subordinates naturally try to reduce the power distance (or inequality) between them and their superiors. Likewise, superiors try to increase the power distance. The societal average is the point of equilibrium where subordinates and superiors are comfortable with the power distance.

Hofstede (1980) directly links the index to trust. Countries with high power distance "exhibit less interpersonal trust and a greater need for organizational controls on the behavior of individuals" (Shane, 1992, p. 299). Moreover, Shane asserts that countries with more per capita lawyers are less trustworthy, because these countries need to write contingent claim contracts (Shane, 1993). Indeed, the power distance index significantly correlates with per capita lawyers $(r=.51$, $\mathrm{p}<0.025$ [Shane, 1993]). Although this relationship is significant, it is not perfectly correlated. For example, India has relatively few lawyers per capita (The Economist, 1992) in spite of its high power distance. Other factors come into play such as the huge population, the relatively lower level of economic activity per 
capita, other types of activities that lawyers might partake (e.g., politics), etc. On the other hand, the United States has relatively high number of lawyers per capita (The Economist, 1992), yet a relatively low power distance (ranks 11 - see Table 1). Nonetheless, the relationship between lawyers and the power index is significant.

The concept of equality and power distance has implications for the entrepreneur/export agent relationship. High power distance countries may be less stable. Subordinates may try to enact changes in the power distance via violent means. Thus, high power distance countries more frequently suffer sudden changes in form of government (i.e., revolutions [Hofstede, 1980]). Similarly, agents from these cultures may act covertly to equalize the entrepreneur/agent relationship; they are likely to act opportunistically. Thus, entrepreneurs should seek strong outcome based relationships in these countries to limit their risk exposure. On the other hand, "a smaller power distance leads to the feasibility of control systems based on trust in subordinates; in larger power distance countries such trust is missing" (Hofstede, 1980, p. 384). Therefore, entrepreneurs entering low power distance countries can risk behavior oriented contracts because there is less danger of opportunistic behavior by the agent.

Shane (1992) adeptly demonstrates that the power distance index correlates highly with trust attributes. Basically, Shane finds that MNCs are apt to engage in foreign direct investment versus licensing when entering countries which are less trustworthy. It is more effective to internalize (even if it increases initial expenses) than rely on opportunistic licensers. Conversely, licensing is more effective if the culture is trustworthy, because the MNC does not have to worry about opportunistic behavior and licensing reduces the initial expenses of establishing a presence in the target country (Shane, 1992).

Table 1 ranks a number of countries on Hofstede's (1980) power distance index. If a country is ranked towards the bottom of the list (high power distance), its culture breeds opportunistic behavior. Thus, when negotiating with an export agent from the Philippines (ranked number 31 on Hofstede's list), entrepreneurs should negotiate for strong outcome based contracts (if they decide to enter the country at all). However, entrepreneurs can feel pretty confident in behavior based contracts with agents from Austria (ranked number 1), because members of this culture are apt to be more trustworthy.

Unlike the large $\mathrm{MNC}$, the smaller entrepreneurial firm typically does not possess the resources to internalize into the target market. Smaller organizations must leverage their relatively constrained resources by reducing up-front expenditures. The export agent strategy can greatly reduce the entrepreneur's initial expenses. The implications of Hofstede's (1980) and Shane's $(1992,1993)$ work is that the entrepreneur should (1) structure the agency relationship with the target country's trustworthiness in mind and (2) possibly avoid those countries with the lowest trustworthiness. If entrepreneurs fail to acknowledge a country's propensity for trustworthiness, they may inappropriately structure the relation- 


\section{Table 1}

\section{Ranking of Countries on the Power Distance Index}

(the higher the rank, the lower the power distance)

\section{Country}

$\begin{array}{lc}\text { Argentina } & 12 \\ \text { Australia } & 9 \\ \text { Austria } & 1 \\ \text { Belgium } & 23 \\ \text { Brazil } & 27 \\ \text { Canada } & 11 \\ \text { Chile } & 20 \\ \text { Colombia } & 24 \\ \text { Denmark } & 2 \\ \text { France } & 25 \\ \text { Germany } & 7 \\ \text { Great Britain } & 7 \\ \text { Greece } & 18 \\ \text { Hong Kong } & 25 \\ \text { Indonesia } & 29 \\ \text { India } & 28 \\ \text { Italy } & 14 \\ \text { Japan } & 15 \\ \text { Korea } & 18 \\ \text { Malaysia } & 31 \\ \text { Netherlands } & 10 \\ \text { Norway } & 4 \\ \text { New Zealand } & 3 \\ \text { Philippines } & 31 \\ \text { Portugal } & 20 \\ \text { South Africa } & 12 \\ \text { Singapore } & 27 \\ \text { Spain } & 16 \\ \text { Sweden } & 4 \\ \text { Switzerland } & 6 \\ \text { Taiwan } & 17 \\ \text { Thailand } & 22 \\ \text { United States } & 11 \\ \text { Venezuela } & 30 \\ & \end{array}$

Adapted from Hofstede (1980)

ship such that they bear too much risk. Likewise, it may be wise for entrepreneurs to avoid entering countries with the lowest trustworthiness because it would require a tight outcome oriented contract. Although such a contract may bring the 
risk to acceptable levels, a contract entered with such negative stipulations often results in poor performance (Bazerman \& Carroll, 1987; Neale \& Northcraft, 1991). The above discussion leads to the final propositions:

Proposition 5a: All else being equal, entrepreneurs should negotiate for a behavior-oriented contract in countries with a high power index ranking (high trustworthiness) and for an outcome-based contract in countries with a low power index ranking (low trustworthiness).

Proposition 5b: All else being equal, entrepreneurs should target countries with a high power index ranking (high trustworthiness) for entry.

\section{Discussion}

As the above dialogue demonstrates, there are a variety of factors that influence the entrepreneur/agent relationship. Optimally, the entrepreneur prefers an outcome-based contract, because it aligns the entrepreneur's and agent's interests (Jensen \& Meckling, 1976). The agent organization is less likely to misrepresent itself (adverse selection), because it is obligated to reach some specified outcome. Furthermore, entrepreneurs are not subjected to the costs of moral hazard since agents are only rewarded for outcomes of their performance. Large geographical separation favors outcome contracts to the extent that outcome-based contracts avoid monitoring costs. However, the entrepreneur may have difficulty finding an agent who will accept an outcome-based contract. Moreover, the negative tone that such a contract conveys may lessen the chance for entry success. Therefore, the entrepreneur needs to assess cultural values in determining the best contracting method. If the culture is one of trust, the entrepreneur can confidently employ a behavior based contract without incurring additional risk.

When entrepreneurs negotiate for a behavior-based contract, they should be aware of possible bonding methods. Adeptly bonding the agent via a letter of credit or some other mechanism may reduce the entrepreneur's monitoring costs associated with a behavior-oriented contract. In fact, adroit bonding mechanisms may reduce the entrepreneur's monitoring costs to the point where it would offset any concessions that the entrepreneur would have to make for the agent to accept an outcome-based contract. Under such a scenario, the behavior-based contract might be more cost effective than an outcome-based contract, especially since it may enhance the trust within the relationship thereby improving the chances for success.

While the pitfalls for a small company seeking international outlets are many, as the U.S. domestic market continues to mature, the best growth opportu- 
nities may reside internationally. If an expansion opportunity arises, the entrepreneur should be cognizant of the agency issue; failure to recognize the agency problem might even affect the entrepreneur's survival. The agency model presented in the current paper illustrates ideal contract desires, the conflict in contract desires between entrepreneurs and export agents, and how these conflicts might be reduced via bonding. Additionally, the concept that behavior oriented contracts lead to greater entry success and, as a result, entrepreneurs should first consider "trustworthy" countries (all else equal) provides powerful suggestions to entrepreneurs about "how to" and "what" countries to enter.

Although Agency Theory provides an excellent basis for evaluating international expansion, an important weaknesses of this perspective needs to be recognized. Agency Theory assumes that the two parties act in a rational, opportunistic way. Thus, agents are assumed to shirk unless they are properly monitored, or obligated under an outcome-oriented contract, or fear reputation repercussions. Other factors currently exogenous to this theory may, however, come into play. For instance, people generally refrain from shirking, because of social norms. While Doz \& Prahalad (1991) rightfully stress the importance of including psychological and social factors into the agency model, it is especially difficult for an entrepreneur investigating a potential international relationship to gauge the agent's psychological or social biases, except at the broadest levels (i.e., cultural biases). Thus, agency prescriptions may still provide a realistic basis for structuring the relationship to maximize survival in a different context.

This paper guides entrepreneurs in contract structuring. The paper applies Agency Theory to a specific application, the entrepreneur's entry into foreign markets. Practitioners may find the paper illuminating when structuring their international relationships. The Agency perspective clarifies the pluses and minuses of different contract options, which might help entrepreneurs decide if foreign expansion is advisable, and ensure that they negotiate for the most effective contract possible. In conclusion, the Agency perspective provides a sound theoretical basis for exploring entrepreneurial international entry strategies and their consequences.

\section{References}

Bazerman, M.H., \& Carroll, J.S. (1987). Negotiator cognition. In B. Staw \& L. Cummings (Eds.) Research in organizational behavior, Vol. 9. (pp. 247-288). Greenwich, CT: JAI Press.

Bergen, M., Dutta, S., \& Walker, O.C. (1987). Agency relationships in marketing: A review of the implications and applications of agency and related theories. Journal of Marketing, 56 (July), 1-24.

Brickley, J.A., \& Dark, F. (1987). The choice of organizational form: The case of franchising. Journal of Financial Economics, 18 (June), 401-420. 
Brokaw, L. (1990). Foreign affairs. Inc., November, 92-104.

Brown, R.H. (1995). The national export strategy. Third Annual Report to the United States Congress.

Conlon, E., \& Parks, J. (1988). The effects of monitoring and tradition on compensation arrangements: An experiment on principal/agent dyads. In F. Hoy (Ed.) Best paper proceedings. (pp. 191-195). Anaheim, CA: Academy of Management.

Contractor, F.J. (1990). Contractual and cooperative forms of international business: Towards a unified theory of modal choice. Management International Review, 30(1), $31-54$.

Donaldson, L. (1990). The ethereal hand: Organizational economics and management theory. Academy of Management Review, 15(3), 369-381.

Doz, Y.L., \& Prahalad, C.K. (1991). Managing DMNC'S: A search for a new paradigm. Strategic Management Journal, 12, 145-164.

A survey of the legal profession. (1992). The Economist, July 18, 55 .

Eisenhardt, K.M. (1989). Agency theory: An assessment and review. Academy of Management Review, 14(1), 57-75.

Eisenhardt, K.M. (1985). Control: Organizational and economic approaches. Management Science, 31, 134-149.

Hennart, J-F. (1990). The transaction cost theory of the multinational enterprise. In C. Pitelis and R. Sugden (Eds.) The nature of the transnational firm, London: Routledge.

Hennart, J-F. (1988). A transaction cost theory of equity joint ventures. Strategic Management Journal, 9(4), 361-374.

Hofstede, G. (1980). Culture's consequences: International differences in work related values, Beverly Hills: Sage.

Jensen, M., \& Meckling W. (1976). Theory of the firm: Managerial behavior, agency costs, and ownership structure. Journal of Financial Economics, 11, 5-50.

Larson, A. (1992). Network dyads in entrepreneurial settings: A study of the governance of exchange relationships. Administration Science Quarterly, 37, 76-104.

Lawless, M.W., \& Price, L.L. (1992). An agency perspective on new technology champions. Organization Science, 3(3), 342-355.

Mahoney, J.T. (1992a). Organizational economics within the conversation of strategic management. Advances in Strategic Management, 8, 103-155. JAI Press. 
Mahoney, J.T. (1992b). The choice of organizational form: Vertical financial ownership versus other methods of vertical integration. Strategic Management Journal, 13, 559 . 584.

McDougall, P.P., Shane, S., \& Oviatt, B.M. (1994). Explaining the formation of international new ventures: The limits of theories from international business research. Journal of Business Venturing, 9(6), 469-487.

Neale, M.A., \& Northcraft, G.B. (1991). Behavioral negotiation theory: A framework for conceptualizing dyadic bargaining. In L. Cummings \& B. Staw (Eds.) Research in Organizational Behavior, 13, pp. 147-190. Greenwich, CT: JAI Press.

Ouchi, W. (1980). Markets, bureaucracies and clans. Administrative Science Quarterly, $25,129-142$.

Oviatt, B.M., \& McDougall, P.P. (1994). Toward a theory of international new ventures. Journal of International Business Studies, 25(1), 45-64.

Pratt, J.W., \& Zeckhauser, R.J. (1985). Principals and agents: The structure of business. Boston: Harvard Business School Press.

Prosak, S.L. (1993). Small businesses are exporting. Business America, 114(24), 2.

Ring, R.S., \& Van de Ven, A.H. (1994). Developmental processes of cooperative interorganizational relationships. The Academy of Management Review, 19(1), 90118.

Rugman, A.M., \& Verbeke, A. (1992). A note on the transnational solution and the transaction cost theory of multinational strategic management. Journal of International Business, 23(4), 761-771.

Rumelt, R.P., Schendel, D., \& Teece, D.J. (1991). Strategic management and economics. Strategic Management Journal, 12, 5-29.

Shane, S.A. (1993). The effect of cultural differences in perception of transaction costs on national differences in the preference for international joint ventures. Asia Pacific Journal of Management, 10(1), 57-69.

Shane, S.A. (1992). The effect of cultural differences in perception of transaction costs on national differences in the preference of licensing. Management International Review, 32(4), 295-311.

Stinchcombe, A.L. (1965). Social structure and organizations. In J. March (Ed.) Handbook of Organizations, (pp. 142-193). Chicago: Rand McNally.

Vesper, K.H. (1990). New venture strategies, Revised Edition. Englewood Cliffs, NJ: Prentice Hall. 
Williamson, O.E. (1988). Corporate finance and corporate governance. The Journal of Finance, 18(3), 567-591.

\section{Appendix \\ Definitions of International Entry Modes}

Export - firm maintains its home production facilities and sells same good/ service that firm sells in domestic market through a contractual agent that gains access to foreign distribution channel.

Licensing - arrangement that allows a foreign firm to purchase the right to manufacture and sell the firm's product within a host country or set of countries. Franchising is a form of licensing.

Joint Venture/Strategic Alliance - entrepreneur joins with another firm to share the risks and resources required to enter international markets; usually with a firm from the host country.

Foreign Direct Investment - direct acquisition and ownership of facilities within host country. 